\title{
Is there a specific visuo-spatial impairment in Parkinsonians?
}

\author{
SERGIO DELLASALA,$*$ GIUSEPPE DI LORENZO, $†$ ANDREA GIORDANO, \\ HANS SPINNLER*
}

From the Neuropsychology Centre and 1st Neurological Clinic of Milan University, ${ }^{*}$ Departments of Neurology $\dagger$ and Bio-engineering $\ddagger$ of the "Clinica del Lavoro" Foundation, Institute of Care and Research, Medical Centre of Rehabilitation, Veruno (NO), Italy

SUMMARY Twenty-five non-demented patients with mild, idiopathic, Parkinson's disease were compared with 25 age and education matched normal controls on a visuo-spatial performance task, whose characteristics were directional forecast, with minimal motor requirement and a maximal spatial load. No statistical support was found for the existence of spatial impairment in these patients.

It is still debated whether dementia should be considered as a regular feature of Parkinson's disease or as limited to a subgroup of patients. There is, however, much evidence to suggest that dementia is likely to be related in some way to Parkinson's disease. ${ }^{1-5}$ Quoted prevalence figures for dementia in Parkinson's disease range from as low as $2 \%^{6}$ based on clinical notes, to $93 \%^{3}$ on psychometric evaluations, the higher percentages being reported in recent years. A convincing interpretation has not yet been given of these differences.

Amongst the cognitive impairments reported in Parkinsonians, visuo-spatial deficits are claimed to be the most frequent. ${ }^{7-32}$ Indeed, they are also maintained to be "unique, specific, and independent" from more widespread dementia. ${ }^{1421263334}$ This finding also gains support from behavioural results of experimental lesions located in the basal ganglia of mammals, ${ }^{123542}$ from subcortical stimulation studies ${ }^{4344}$ and from the cognitive impairment produced by surgical lesions of basal ganglia in human beings. ${ }^{45-47}$ Both experimental and neurosurgical lesions, as well as stimulation studies, however, are not limited to the nigro-striatal pathways. Finally it is worth mentioning that visual abnormalities have been found in Parkinson's disease, the occurrence of which does not seem to be due to motor impairment. ${ }^{48-50} \mathrm{~A}$ few studies, however, have failed to find visuo-spatial

Address for reprint requests: Dr $\mathrm{H}$ Spinnler, Centro di Neuropsicologia dell'Universita di Milano, via F. Sforza, 35-20122 Milano, Italy.

Received 14 June 1985 and in revised form 13 November 1985. Accepted 3 February 1986 differences between Parkinsonians and normal controls. $^{265157}$ This inconsistency may be due to differences in patient-control selection criteria, in severity, length and age of onset of the disease, in the difficulty of the task and in its motor requirements, in the presence of time-constraints in the task (a variable which obviously penalises bradykinetic Parkinsonians), in the contribution of depression in medical and surgical treatments, in the presence of other risk factors for cognitive impairment such as normal ageing, associated cerebrovascular disorders, Alzheimer-like or extra-nigral degenerative disorders. Unfortunately there are few studies which take into account the majority of these sources of biases. ${ }^{525358-60}$

To study the hypothesis that a bilateral degeneration limited to the nigral dopaminergic system causes a specific visuo-spatial impairment, we have studied a homogeneous sample of mildly disabled patients with idiopathic Parkinson's disease. All were levodopa responders, never exposed to anticholinergic drugs. None had signs or symptoms of other cognitive disorders or of depression. We used two visuo-spatial tasks designed to test the capacity of performing a spatial mental operation. We resorted to a "spatial forecast" test as it has been said that Parkinsonians fail to match the direction of a target and spontaneously fail to make predictions. ${ }^{61}{ }^{62} \mathrm{On}$ the other hand, normal subjects use prediction in the immediate control of behaviour, especially when perceptual-motor skills are to work. ${ }^{63}$

\section{Subjects and methods}

(1) Experimental subjects (a) Parkinsonians: 25 (9 males and 
16 females) mildy disabled, right-handed patients with bilateral idiopathic Parkinson's disease were selected from a series of 94 Parkinson's disease in-patients following the criteria set out in table 1 . Their mean age was 62.9 years SD 6.5 (range: 49-69), mean educational level was 6.1 years SD $2 \cdot 4$ (range: 3-13), mean length of illness was 5.8 years SD 4.3 (range: 1-18), mean daily intake of levodopa was 378 (SD $251) \mathrm{mg} /$ day (range: $0-1000$ ).

Patients were closely questioned by means of a formal inquiry ${ }^{65}$ to discover any sign of every-day impairment of their ability to cope socially; impaired patients were excluded from the study. Those included underwent psychometrical testing for intelligence, memory and learning, and language, since we were interested in tackling the hypothesis of a specific, non dementia-linked, cognitive disorder affecting Parkinsonians.

(b) Two groups of normal subjects were studied: (1) 321 normals studied independently from the present research (Capitani, Della Sala, Spinnler, in preparation) provided the normative data for the cognitive tests. Performance on each of the tests employed (see under heading (2), (b) is related to age, education and sex in normals. The observed score of each performance was adjusted using a linearly co-variated model of these variables. Instead of using the adjusted scores, they were converted into "equivalent scores", which are expressions of the location of the adjusted test-score along the distribution of scores of the normal population. This conversion was done on a statistical inferential basis. The adjusted scores were classified into five categories ( 0 to 4) with an ordinal relationship. Limits for these category- scores were as follows: the scores lower than the one-sided $5 \%$ tolerance limits of the population (inferred with $95 \%$ confidence) were classified 0 , scores higher than the median value of the sample, i.e. above the $50 \%$ of the population, were classified 4 . For the intermediate points boundaries were set with reference to percentage partition of the left half of a normal distribution into four regions identified by a division into three equal parts of the normal deviate corresponding to the 0.05 tolerance limit. The classification of the individual corrected scores into this five point scale allows a direct comparison of the performance of every new subject for different tests in terms of his location on the normal population's score range. For the present study patients were included when they had no more than one 0 -allocation on the four tests listed below. The percentages of patients for each of the centile positions in the psychometrical features considered are set out in table 2 . It is apparent that the distribution of the Parkinsonians does not exactly fit that of the whole sample of 321 normals. Chi-square analysis for the four tests (Raven Progressive Matrices, Word Span, Free Recall and Token Test, respectively: 16.30 (p < 0.01); 14.07 $(\mathrm{p}<0.01) ; 31.10(\mathrm{p}<0.001) ; 17.18(\mathrm{p}<0.01)$ revealed a general leftwards shift and indicates a general psychometric deterioration of the Parkinsonians.

(2) A second group of controls specifically entered this study: 25 age-education matched controls (6 males and 19 females) often relatives of the Parkinsonians, found to be normal on a formal inquiry and on a standardised neurological examination, acted as an unpaid and naive control group for the visuo-spatial and the Screw Rotation task.

Table 1 Constraints of selection employed to form the experimental example of Parkinsonians $(N=25)$

Age: younger than 70 years;

Handedness: $100 \%$ right-handed on Oldfield's Inventory ${ }^{64}$.

Education: at least 3 years;

No evidence of depression on a modified version of the Hamilton's Depression Scale; score range: 0 (best score)-39; actual average: 8.9

SD 3.1;

Never exposed to anticholinergic drugs;

Minimal most responsive treatment unmodified since at least 15 days before testing;

NUDS ability score above $50 \%$ (that is, above 25 ); actual average: 39.84 SD 6.13;

Hoehn and Yahr's Scale: stage 3 or less; actual average: 2.40 SD 0.64;

Never more than $1000 \mathrm{mg}$ daily intake of levodopa (Madopar* Ré or Sinemet* Ré);

From history, never overt behavioural evidence of demential traits in every-day coping abilities; ${ }^{65}$

At present stage, no asymmetrical neurological involvement;

No lung, kidney, liver or heart chronic failure;

No stereotactic surgery in the past;

No association of psychiatric treatment;

No more than one 0 -equivalent score out of the 4-test neuropsychological set (see text, heading (2), (b)

Table 2 Psychometric features of Parkinsonians $(N=25)$. Centile allocation* on the distribution of the normal population (drawn from a sample of 321 normal subjects), of Parkinsonians according to their age, educational level and sex adjusted scores; numerosity in brackets. Chi-squared for the four tests are respectively $(d f=4): 16 \cdot 30 ; 14 \cdot 07 ; 31 \cdot 10 ; 17 \cdot 18($ all yielding a $p<0.01$ )

\begin{tabular}{|c|c|c|c|c|c|}
\hline Equivalent Scores & 0 & 1 & 2 & 3 & 4 \\
\hline $\begin{array}{l}\text { Normals Centiles } \\
\text { Raven PM } \\
\text { Word span } \\
\text { Free recall } \\
\text { Token Test }\end{array}$ & $\begin{array}{c}<5(9) \\
12(3) \\
0(0) \\
20(5) \\
8(2)\end{array}$ & $\begin{array}{l}5-10(25) \\
20(5) \\
8(2) \\
8(2) \\
12(3)\end{array}$ & $\begin{array}{l}10-25(52) \\
20(5) \\
28(7) \\
36(9) \\
40(10)\end{array}$ & $\begin{array}{l}25-50(74) \\
32(8) \\
48(12) \\
28(7) \\
28(7)\end{array}$ & $\begin{array}{c}>50(161) \\
16(4) \\
16(4) \\
8(2) \\
12(3)\end{array}$ \\
\hline
\end{tabular}

*Allocation with $95 \%$ confidence and $5 \%$ tolerance. 
Their mean age was 63.2 years SD 6.5 (range 49-69) and their mean educational level was $6 \cdot 3$ years SD $3 \cdot 3$ (range 3-17).

\section{(2) Testing procedure}

(a) Directional Forecast Assessment: Two "directional forecast" tests were used to examine two levels of difficulty on visuo-spatial function. Subjects had to indicate their judgements by means of a pointer activated by a rotating handle. The pointer allowed the patients to indicate where they thought the extrapolation of an inclined line, depicted on the
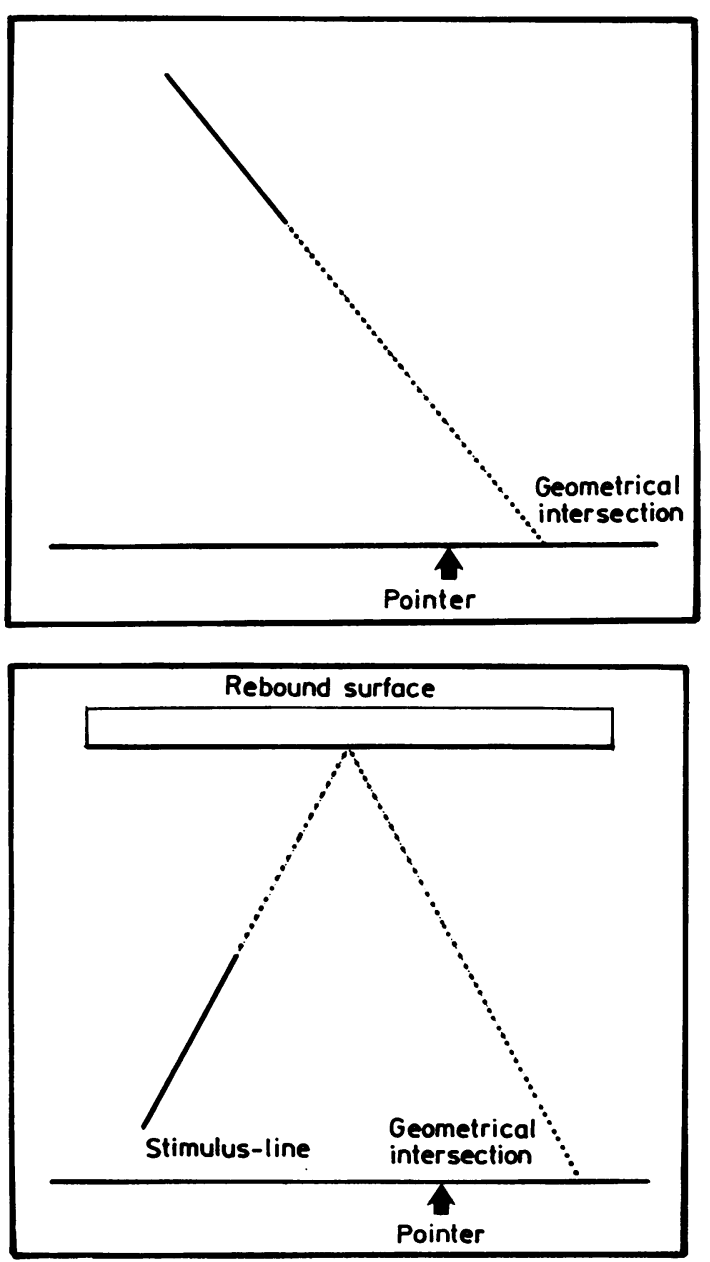

Fig 1 Devices of Experiment 1 (above) and Experiment 2 (below). Length of the directional stimulus was either 3, 6 or $12 \mathrm{~cm}$; angles of the slope varied from $5^{\circ}$ to $35^{\circ}$. Each segment was always displayed from top to bottom in Experiment 1 and bottom to top in Experiment 2, randomly from left to right or vice-versa. The pointer moved horizontally. Dotted line shows the geometrical intersection as well as the run of an ideal perfect forecast. screen of a personal computer, would intercept a $19 \mathrm{~cm}$ long base-line. Eighteen lines of three different lengths (respectively, six of $3 \mathrm{~cm}$, six of $6 \mathrm{~cm}$, and six of $12 \mathrm{~cm}$ ) were displayed in two different settings, in a fixed random sequence. In Experiment 1 the directional forecast had to be extrapolated from a single top-bottom line (fig 1a). In Experiment 2 the directional forecast had to be extrapolated from an upward line pointing against a "rebound wall" and thereafter reflected downwards to intercept the base-line (fig lb). All subjects used their right (dominant) hand.

Formal tests in both experimental seitings were preceded by as many practice trials with a $10 \mathrm{~cm}$ long segment, as needed to allow the examiner to be sure that the subject understood the task. Experiment 1 was always run before Experiment 2; the whole testing session for the assessment of the directional forecast lasted about 15 minutes. In the test trials there was no time limit: subjects were allowed to change their answer until they felt that the final position of the pointer was the best possible solution. An inaccuracy score was measured in units (monitor pixels) of distance from the geometrically assessed intercept. Both absolute and left/right scores were given. Each subject was given three scores for each experiment, each being the average of six trials for a given segment length.

(b) Psychometric testing of general cognitive competence: Logical Intelligence assessed by means of Raven's "Progressive Matrices" 1938. Sets A, B, C and D were used within an overall $30-\mathrm{min}$ time limit. Overall score ranged from 0 to $48 .{ }^{66}$

Short-Term Memory: Immediate Verbal Forward Span. Disyllabic common words were used. Forward answers were requested with stress on seriality. Span level was assigned whenever two out of three strings of words were correctly repeated and only in this case the next level was tried. ${ }^{67}$

Long-Term Memory: Restricted Verbal Reminding Free Recall Test. Following Buschke and Fuld's procedure, ${ }^{68}$ the patient was asked to recall as many items as possible out of a 10 disyllabic word string. Trials were run until two subsequent flawless repetitions were achieved (achievement of learning "criterion") up to a maximum of 18 trials. Testing lasted approximately $20 \mathrm{~min}$. For the purpose of this study only the Long Term Storage Capacity score was used (range: 0-180). ${ }^{69}$

Language: Token Test. De Renzi and Faglioni's shortened procedure $^{70}$ was followed. Score ranged from 0 to 36 .

(c) Screw Rotation Task: the patient was required to screw a nut (18 mm external diameter) up a $18 \mathrm{~cm}$ long bolt allowing to resort only to coordinated movements of the index finger and the thumb of the right (preferred) hand. The task was repeated five times. Score was the average time required to complete the task.

(3) Statistical procedures. Since accuracy-data of both groups were distributed according to a pattern that was not significantly different from normal distribution, and since Experiment 1 and Experiment 2 tapped a similar function of directional forecast, a single 2 (the experimental groups: Parkinsonians and controls) $\times 3$ (the three different lengths of the segments) $\times 2$ (the two experimental settings) ANOVA for repeated measures was used; one factor between (groups) and two factors within (length of segments and experimental settings). Correlations and regressions were worked out parametrically. 


\section{Results}

On the screw rotation task Parkinsonians achieved a score (18.48 SD 7.42) that was significantly different ( $t$ $=3.46, \mathrm{df}=24, \mathrm{p}<0.01)$ from that of normal controls (12.77 SD 4.21). Even these mild Parkinsonians (all on optimal levodopa dosage) showed the motor-speed impairment.

The degree of inaccuracy of the directional forecast in each experimental condition in Parkinsonians and normal controls is shown in fig 2 . Experiment 2 (that is, with the "rebound surface") was the more difficult task, giving rise to a greater overall inaccuracy. In both experiments the shortest (that is, $3 \mathrm{~cm}$ long) segment produced the poorest directional forecast (see also fig 3).

The results of the $2 \times 3 \times 2$ ANOVA for the inaccuracy scores, were as follows: whereas the second order interaction (that is, interaction between experimental groups, length of segments and experimental settings) clearly fell far below significance $(\mathrm{F} 1,48=$ $2 \cdot 162$, p: NS), two out of three first order interactions achieved significance: (1) interaction between experimental groups and length of segments $(F$ 2,96= $3.470, p<0.05$ ) indicating that groups were sensitive to the length of the segments acting as visuo-spatial stimulus for directional forecast. One can infer that Parkinsonians were more sensitive than normal controls (that is, more inaccurate) to the shortest segment (that is, to the most difficult one). (see Fig 3). (2) interaction between segment length and the experimental setting $(F 2,96=8.003, p<0.001)$ indicating that the increase in forecasting difficulty through the 3 segment lengths (F 2,96 $=58.818, p<0.0001)$ and

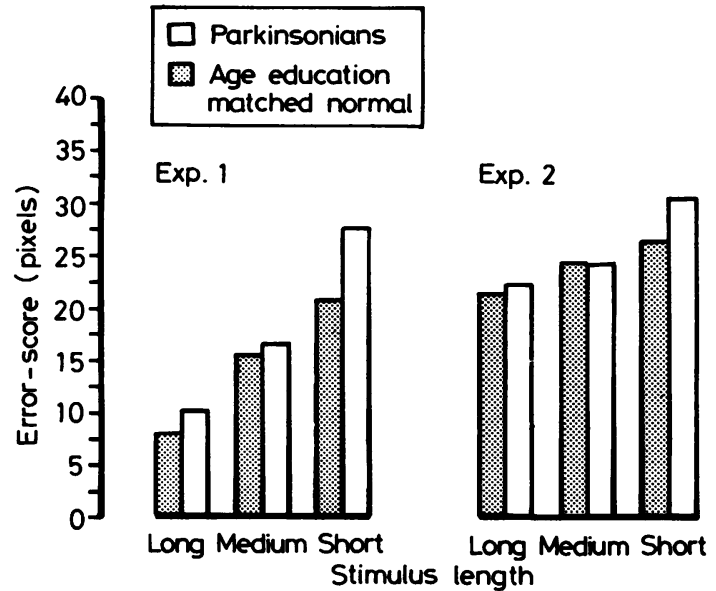

Fig 2 Mean error scores (pixels) of the Directional Forecast in Experiment 1 and Experiment 2 for the Parkinsonians and the matched controls in, respectively, the long, medium and short segment.
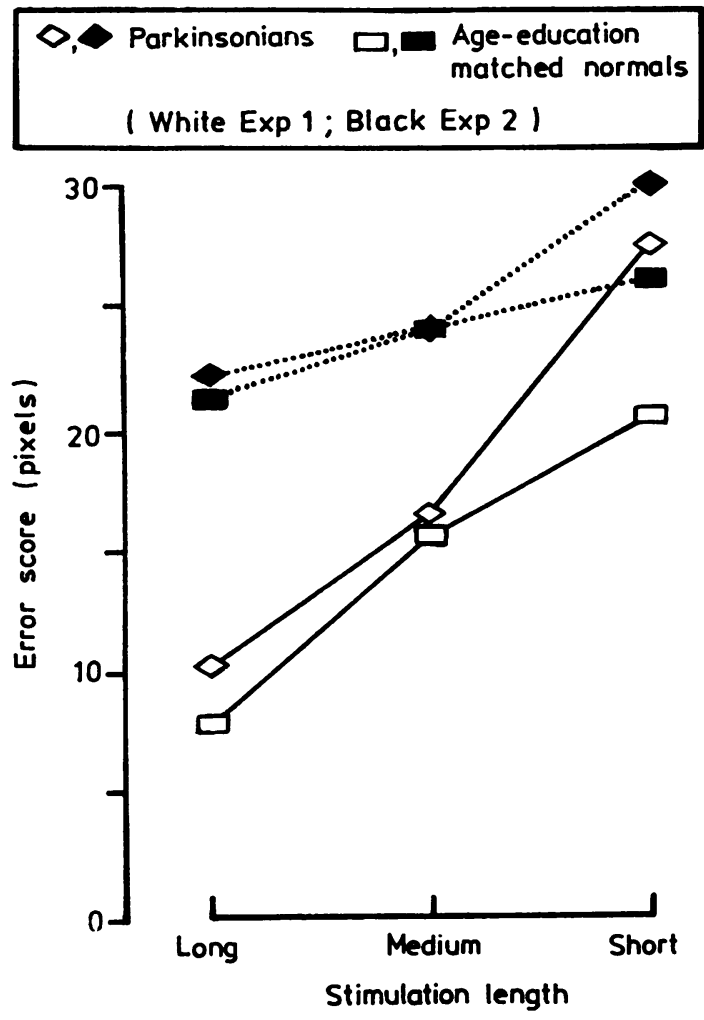

Fig 3 Graphical lay-out of the interaction between the two experimental groups and the three lengths of the segments, underscoring the outstanding role of the shortest segment. Key: white = Experiment 1, black = Experiment 2; rectangles $=$ controls, diamonds $=$ Parkinsonians .

through the two experimental settings (F 1,48= $34.936, p<0.0001)$ is more than additive.

Summing up, Parkinsonians were as inaccurate in their directional forecast as normal controls. Actually the experimental groups acted as a non-significant source of variability $(F 1,48=2 \cdot 162, p$ : NS). There was, however, irrespective of the experimental setting, a tendency of Parkinsonians to be somewhat more sensitive than controls to the less informative stimulus (that is the shortest segment). To solve the ambiguity produced by the contrast of non-significant higher order interaction compared to lower level significant interactions (chiefly between experimental groups and length of the segments), we resorted $a$ posteriori to two separate $3 \times 2$ ANOVAs: one for each experimental setting. In both conditions, the Parkinsonians vs normal controls difference turned out to be unequivocally non-significant (Experiment 1: F 2,96 $=2.703$; Experiment $2: \mathrm{F} 2,96<1$ ), whereas, in both, segment length appeared to be a highly significant 
source of variability acting independently of experimental groups.

Three further analyses were undertaken to clarify marginal details of the performance of Parkinsonians: (1) the same statistical analysis was run on signed error scores, that is for each trial of each experimental subject, noting whether the error was committed left or right of the ideal interception point (see fig la and b). The outcome was only marginally different from that found previously: length of segments remained highly significant $(F 2,96=24.453 ; p<0.0001)$ as well as the interaction between segment length and experimental setting (F 2,96 = 13.355; p < 0.0001), whilst both the experimental setting and the interaction between groups and length of segments fell short of significance (respectively, F 1,48 = 1.097 and $F 2,96$ ). Both group difference and the second order interaction remained far below significance (respectively $F 1,48<1$ and $F 2,96<1$ ). Taking these findings together, they rule out a systematical directional trend in giving rise to the mean error scores set out in figs 2 and 3 . Hence we are confident that the dependent variable employed in this study actually reflects an inaccuracy behaviour and not a directional trend in committing forecast errors.

(2) The role of length of illness, daily levodopa intake, overall severity (NUDS-scores) and motor impairment measured by means of the Screw Rotation Test, on the degree of inaccuracy of Parkinsonians in the different test conditions was statistically tested both by means of linear regression and parametric correlation. Both approaches yielded values far below significance, Regression's F-ratio (df always 1,23 ) being respectively $0.137 ; 2.402 ; 0.097$; 0.030 , while the Pearson's rhos were: $0.07 ;-0.30$; $-0.06 ;-0.03$.

(3) Finally the directional forecasts of the five Parkinsonians with definitely predominant tremor were compared with those of 13 with predominant bradykinesia (it was not possible to assign the remaining patients to one of the two above mentioned subgroups with the accuracy necessary to be useful in this experiment). This analysis failed to show any significant inter-group difference $(\mathrm{F} 1,16=2 \cdot 289$, $\mathrm{p}$ : NS), the shortest segment being the most difficult one irrespective of the neurological subgroup (that is, tremulous vs bradykinetic) considered. This finding is at variance with several claims that bradykinetic Parkinsonians have more visuo-spatial cognitive impairment ${ }^{14}$ than those with tremor; but it is in agreement with Boller et al's findings. ${ }^{21}$

\section{Discussion}

Our results suggest that visuo-spatial disorders, assessed by means of a procedure with no time limit which calls only minimally for motor skills, and maximally stresses a strictly spatial mental ability, are not a feature of Parkinsonians, at least in the mild stage of their disease and with the exclusion of all patients with dementia. This conclusion is clearly at variance with most neuropsychological studies carried out on Parkinsonians. ${ }^{7-32}$

The lack of difference between Parkinsonians and normal controls in a set of answers of spatial accuracy may be due to the careful selection of patients. The exclusion of patients with dementia reduces the group to a sample of mildly disabled Parkinsonians, whose disease might not have lasted long enough to have caused a widespread enchroachment of neuronal damage outside the nigro-striatal core. The visuospatial disorders found elsewhere might have been the result either of inclusion of demented patients, or, alternatively, of more severely affected patients with more wide-spread damage to the nigral system. Some further information regarding the former point might be achieved by comparing carefully matched Parkinsonians with patients affected by dementia of the Alzheimer-type. As far as the latter point is concerned, a longitudinal study is required. Also, it could be argued that levodopa treatment corrects both the motor impairment and the spatial or even the overall cognitive deficiencies sometimes apparent in the disease. However, there are no pharmacological studies relating true spatial impairment of Parkinsonians to levodopa intake, and our regression and correlation data lack significance. In an attempi to draw conclusions at this point, we are strongly inclined to attribute the discrepancy between our findings and those of other researchers to an intentional sample-bias. The negative outcome of this study may be due to the extremely strict criteria for selection of the patients.

Some problems with testing should be raised. There is no evidence that the testing device and procedure could actually have provided help to Parkinsonians. Moreover, the test neither appeared to be too easy (there were no ceiling scores in either group) nor did it fail to fit the spatial requirements crucial to answering the general problems at issue. It seems that the test is devoid of any important motor features (see also the lack of correlations with the Screw Rotation Test scores) and of any time-constraint. This makes it comparable only to a limited degree with most visuospatial testing approaches hitherto employed (for example, all the studies considering the performance subtests of WAIS as spatial). It is worth mentioning that the purest spatial tests (that is, those nearly free from any motor output) did not differentiate between Parkinsonians and normal controls in Boller et al's study. ${ }^{21}$ We suspect that it is not the strictly spatial feature of the several "visuo-spatial" tests employed that highlight a specific Parkinsonian impairment. 
Hence part of the discrepancy between our results and those of most of the other authors could be linked to a test-bias, this is to say that mild Parkinsonians are insensitive to tests with a nearly exclusively spatial load, simply because they do not have any true spatial disorder. Both sample-biases and test-biases highlight the methodological problems in investigating cognitive impairments in Parkinsonians and making general inferences. A final point is that none of our Parkinsonians received anticholinergic treatment. It is a hypothesis with some experimental support ${ }^{71-74}$ that anticholinergics are liable to interfere with cognition (but usually data refer to memory and not to strict spatial performances).

Though it is hazardous to draw conclusions from a set of statistically non-significant results in a highly selected sample of patients, we are strongly inclined to think that purely spatial impairments are not part of specific cognitive disorders in Parkinson's disease as long as its dopaminergic imbalance is confined to the nigro-striatal system. It could, however, be inferred that spatial impairment is the consequence of a widespread, possibly cortical, extra-nigral degenerative process, whose nature could be akin or even identical to that found in Alzheimer disease.

The authors thank Giulio Vidotto, $\mathrm{PhD}$, for statistical counselling, Francois Boller, MD, and Erminio Capitani, MD, for their helpful advice on the first draft of this paper and Fabio Comazzi for technical assistance.

The paper was presented by SDS at the Joint Meeting of the Polish and Italian Societies of Neurology, April 21,1985 , Rome. The research was partly supported by a grant of the Consiglio Nazionale delle Ricerche (no. 8001829) to the Neuropsychology Centre of the University of Milan.

\section{References}

${ }^{1}$ Lieberman A, Dziatolowski M, Kupersmith $\mathrm{M}$, et al. Dementia in Parkinson disease. Ann Neurol 1979;6: 355-9.

${ }^{2}$ Martin WE, Loewenson RB, Resch JA. Parkinson's disease: clinical analysis of 100 patients. Neurology 1973;23:783-90.

${ }^{3}$ Hoehn MM, Yahr MD. Parkinsonism: onset, progression and mortality. Neurology 1967;17:427-42.

${ }^{4}$ Martilla RJ, Rinne VK. Dementia in Parkinson's disease. Acta Neurol Scand 1976;54:431-41.

${ }^{5}$ Pollack M, Hornabrook RW. The prevalence, natural history and dementia of Parkinson's disease. Brain 1966;89:429-48.

${ }^{6}$ Patrick HT, Levy DM. Parkinson's disease. A clinical study of one hundred and forty-six cases. Arch Neurol Psych 1922;7:711-20.

${ }^{7}$ Pirozzolo FJ, Hansch EC, Mortimer JA, Webster DD, Kuskowski MA. Dementia in Parkinson disease: a neuropsychological analysis. Brain and Cognition 1982;1:71-83.

${ }^{8}$ De Lancy Horne DJ. Performance of delayed response tasks by patients with Parkinsonism. J Neurol Neurosurg Psychiatry 1971;34:192-4.

${ }^{9}$ Botez MI, Barbeau A. Neuropsychological findings in Parkinson's disease: a comparison between various tests during long-term levodopa therapy. Int J Neurol 1975;10:222-32.

${ }^{10}$ Danta G, Hilton RD. Judgement of the visual vertical and horizontal in patients with Parkinsonism. Neurology 1975;25:43-67.

${ }^{11}$ Proctor F, Riklan M, Cooper ST, Teuber HL. Judgement of visual and postural vertical by Parkinsonian patients. Neurology 1964;14:287-93.

${ }^{12}$ Teuber HL, Proctor F. Some effects of basal ganglia lesions in subhuman primates and men. Neuropsychologia 1964;2:85-93.

${ }^{13}$ Bowen FP, Hoehn MM, Yahr MD. Parkinsonism: alterations in spatial orientation as determined by a route-walking task. Neuropsychologia 1972;10:355-61.

${ }^{14}$ Mortimer JA, Pirozzolo FJ, Hansch EC, Webster DD. Relationship of motor symptoms to intellectual deficits in Parkinson disease. Neurology 1982;32:133-7.

${ }^{15}$ Asso D. WAIS scores in a group of Parkinson patients. Br J Psychiatry 1969;115:555-6.

${ }^{16}$ Bentin S, Silverberg R, Gordon HW. Asymmetrical cognitive deterioration in demented and Parkinson patients. Cortex 1981;17:533-44.

${ }^{17}$ Loranger AW, Goodell H, McDowell FH, Lee JE, Sweet RD. Intellectual impairment in Parkinson's syndrome. Brain 1972;95:405-12.

${ }^{18}$ Matthews CG, Haaland KY. The effect of symptom duration on cognitive and motor performance in Parkinsonism. Neurology 1979;29:951-6.

${ }^{19}$ Reitan RM, Boll TJ. Intellectual and cognitive functions in Parkinson's disease. J Consult Clin Psychol 1971; 37:364-9.

${ }^{20}$ Albert ML. Subcortical dementia. In: Katzman R, Teny RD, Bick KL, eds. Alzheimer's Disease, Senile Dementia and related disorders. Raven Press, New York, 1978:173-80.

${ }^{21}$ Boller F, Passafiume D, Keefe NC, Rogers K, Morrow L, Kim Y. Visuospatial impairment in Parkinson's Disease. Role of perceptual and motor factors. Arch Neurol 1984;41:485-90.

${ }^{22}$ Hansch EC, Kuskowski MA, Pirozzolo FJ. Mortimer JA. Visual-spatial perception and Parkinson's disease. INS Bull (Sept 82), 23.

${ }^{23}$ Villardita C, Smirni P, La Pira F, Zappala G, Nicoletti F. Mental deterioration, visuoperceptive disabilities and constructional apraxia in Parkinson's disease. Acta Neurol Scand 1982;66:112-20.

${ }^{24} \mathrm{Yahr}$ MD, Proctor-Bowen F. Intellectual deficits in Parkinsonism. Int J Neurol 1975;10:280-1.

${ }^{25}$ Flowers K. Some frequency response characteristics of Parkinsonism on pursuit tracking. Brain 1978;101: 19-34.

${ }^{26}$ Bowen FP. Behavioural alterations in patients with basal ganglia lesions. In Yahr MD. eds. The Basal Ganglia. Raven Press, New York 1976:169-77.

${ }^{27}$ Levita E, Riklan M, Cooper IS. Cognitive and perceptual performance in Parkinsonism as a function of age and 
neurological impairment. J Nerv Ment Dis 1964;139: 516-20.

${ }^{28}$ Martin WE, Loewenson RB, Resch JA, Baker AB. Parkinson's disease: clinical analysis of 100 patients. Neurology 1973;23:789-90.

${ }^{29}$ Direnfeld LK, Albert ML, Volicer L, Langlais PJ, Marquis J, Kaplan E. Parkinson's disease. The possible relationship of laterality to dementia and neurochemical findings. Arch Neurol 1984;41:935-41.

${ }^{30}$ Meier MJ, Martin WE. Intellectual changes associated with levodopa therapy. $J A M A$ 1970;213:465-6.

${ }^{31}$ Portin R, Rinne UK. Neuropsychological responses of Parkinsonian patients to long term levodopa treatment. In: Rinne UK, Klinger M, Stamm G, eds. Parkinson's disease. Current progress, problems and management. Amsterdam: Elsevier, 1980:270-304.

${ }^{32}$ Bowen FP, Burns MM, Brady EM. Yahr MD. A note on alterations of personal orientation in Parkinsonism. Neuropsychologia 1976;14:425-9.

${ }^{33}$ Boller F. Mental status of patients with Parkinson disease. J Clin Neuropsychol 1980;2:157-82.

${ }^{34}$ Mayeux R. Depression and dementia in Parkinson's disease. In: Marsden CD, Fahr S, eds. Movement Disorders. 1982, London: Butterworth.

${ }^{35}$ Potegal M. Role of the caudata nucleus in spatial orientation of rats. J Comp Physiol Psychol 1969;69:755-764.

${ }^{36}$ Pohl W. Dissociation of spatial discrimination following frontal and parietal lesions in monkeys. Ph.D thesis. G. Washington University, Washington DC cited by Stern Y. In: Mayeux R, Rosen WG, eds. The dementias Raven Press, New York 1983:198.

${ }^{37}$ Caan WC, Stein JF. The effect of coding globus pallidus on manual tracking in trained rhesus monkeys. J Physiol 1979;293:69-75.

${ }^{38}$ Rosvold HE. The frontal lobe system: cortical-subcortical interrelationships. Acta Neurobiol Exp (Warsz) 1972;32:439-60.

${ }^{39}$ Teuber HL. Complex functions of basal ganglia. In: Yahr MD eds. The Basal Ganglia Raven Press, New York, 1976:151-68.

${ }^{40}$ Thomson R. Localization of the "maze memory system" in the white rat. Physiol Psychol 1974;2:1-7.

${ }^{41}$ Chorover S, Gross C. Caudate nucleus lesions: behavioural effects in the rat. Science 1963;141:826.

${ }^{42}$ Gross C, Chorover S, Cohen SM. Caudate, cortical, Hippocampal and dorsal thalamus lesions in rats: alteration and Hebb-Williams maze performance. Neuropsychologia 1965;3:53-68.

${ }^{43}$ Cohen SM. Electrical stimulation of cortical-caudate pairs during delayed successive visual discrimination in monkeys. Acta Neurobiol Experim 1972;32:211-33.

${ }^{44}$ Fedio P, Van Buren JM. Memory and perceptual deficits during electrical stimulation in the left and right thalamus and parietal subcortex. Brain Lang 1975;2:78-100.

${ }^{45}$ Riklan M. Levita E. Subcortical Correlates of Human Behaviour. Baltimore: Williams and Wilkins, 1969.

${ }^{46}$ Meier MJ, Story JL. Selective impairment of Porteus Maze test perfomances after right subthalamectomy. Neuropsychologia 1976;5:181-9.

${ }^{47}$ Perret E, Kohenof M, Siegfried J. Influences des lesions thalamiques unilaterales sur les fonctions intellectuelles, mnesique et d'apprendissage des malades Parkin- soniens. Neuropsychologia 1969;7:79-88.

${ }^{48}$ Bodis-Wollner I, Yahr MD. Measurements of visual evoked potentials in Parkinson's disease. Brain 1978;101:661-71.

${ }^{49}$ Bodis-Wollner I, Yahr MD, Mylin LH. Non-motor functions of the basal ganglia. In: Hassler RG, Christ JF eds. Parkinson Specific motor and Mental Disorders Raven Press 1984:289-98.

${ }^{50}$ Bodis-Wollner I, Yahr MD, Thornton J. VEPs and the severity of Parkinson's disease. In: Rose C, Capildeo R. eds. Research Progress in Parkinson's Disease. Pitman Med Bath (Engl); 1981:126-37.

${ }^{51}$ Levita E, Riklan M. Integrative functions in Parkinsonism. Percept and Mot Skill 1970;31:379-85.

${ }^{52}$ Lees AJ, Smith E. Cognitive deficits in the early stages of Parkinson's disease. Brain 1983;106:257-70.

${ }^{53}$ Talland GA. Cognitive function in Parkinson's disease. $J$ Nerv Ment Dis 1962;135:196-205.

${ }^{54}$ Stern Y, Mayeux R, Coté L. Reaction time and vigilance in Parkinson's disease. Possible role of Norepinephrine metabolism. Arch Neurol 1984;41:1086-9.

55 Boller F. Visuospatial impairment in Parkinson disease: role of perceptual and motor factors and of disease stage. Unpublished doctoral dissertation cited by Mortimer JA, Christensen KJ, Webster DD, in "Parkinson Dementia" in: Vinken PJ, Bruyn GW, Klawans HL eds. Neurobehavioural Disorders Amsterdam: Elsevier (in press).

${ }^{56}$ De Lancy Horne DJ. Performance on delayed response task by patients with Parkinsonism. J Neurol Neurosurg Psychiatry 1971;34:192-4.

${ }^{57}$ Brown RG. Visuospatial function in Parkinson's disease. EBBS Workshop on Clinical Neuropsychology. Zurich, April 9-11, 1985; Abstracts: 10.

${ }^{58}$ Mindham RHS, Ahmed SWA, Clough CG. A controlled study of dementia in Parkinson's disease. J Neurol Neurosurg Psychiatry 1982;45:969-74.

${ }^{59}$ Mettler FA, Crandell A. Relationship between Parkinsonism and psychiatric disorders. J Nerv Ment Dis 1959;129:551-63.

${ }^{60}$ Rafal RD, Posner MI, Walker JA, Friedrich FJ. Cognition and the basal ganglia separating mental and motor components of performance in Parkinson's disease. Brain 1984;107:1083-94.

${ }^{61}$ Flowers K. Lack of prediction in the motor behaviour of Parkinsonism. Brain 1978;101:35-52.

${ }^{62}$ Stern Y, Mayeux R, Rosen J, Ilson J. Perceptual motor dysfunction in Parkinson's disease: a deficit in sequential and predictive voluntary movements. $J$ Neurol Neurosurg Psychiatry 1983;46:145-51.

${ }^{63}$ Gregory RL. On how little information controls so much behaviour. Ergonomics 1970;13:25-35.

${ }^{64}$ Oldfield RC. The assessment and analysis of handedness: The Edinburgh inventory. Neuropsychologia 1971;9:97-113.

${ }^{65}$ Della Sala S, Nichelli P, Spinnler H. An Italian series of patients with organic dementia. Ital J Neurol Sci 1986;7:27-41.

${ }^{66}$ Raven JC. Progressive Matrices 1938. Edizione Italiana Organizzazione Speciale, Firenze, 1954.

${ }^{67}$ Della Sala S, Nespoli A, Ronchetti E, Spinnler H. Does chronic liver failure lead to chronic mental impairment? In: Advances in Hepatic Encephalopathy and Urea cycle 
Diseases, Karger, Basel, 1984:448-56.

${ }^{68}$ Buschke H, Fuld PA. Evaluating storage, retention and retrieval in disordered memory and learning. Neurology 1974;24:1019-25.

${ }^{69}$ Della Sala S, Spinnler H. "Indifference Amnesique" in a case of global amnesia following acute brain-hypoxia. Europ Neurol 1986;25:98-109.

${ }^{70}$ De Renzi E, Faglioni P. Normative data and screening power of a shortened version of the Token Test. Cortex 1978;14:41-9.

${ }^{71}$ Drachman DA, Leavit J. Human memory and the cholinergic system: A relationship to aging? Arch Neurol
1974;30:113-21.

${ }^{72}$ Sitaram N, Weingarten H, Gillin JC. Human serial learning: Enhancement with arecholine and choline and impairment with scopolamine. Science 1978;201:274-6.

${ }^{73}$ Sadeh M, Braham J, Modan M. Effects of anticholinergic. drugs on memory in Parkinson's disease. Arch. Neurol 1982;39:666-7.

${ }^{74}$ Syndulko K, Gilden ER, Hansch EC, Potvin AR, Tourtellotte WW, Potvin JH. Decreased verbal memory associated with anticholinergic treatment in Parkinson's disease patients. Internat J Neurosc 1981;14:61-6. 